\title{
VARIAÇÕES NOS TEORES DE CARBONO ORGÂNICO EM FUNÇÃO DO DESMATAMENTO E REVEGETAÇÃO NATURAL DO SOLO
}

\author{
SOIL ORGANIC CARBON VARIATIONS DUE TO DEFORESTATION AND \\ NATURAL REGENERATION
}

\author{
Sidinei Leandro Klöckner Stürmer ${ }^{1}$ Otavio Bagiotto Rossato ${ }^{2}$ André Carlos Cruz Copetti ${ }^{3}$ \\ Danilo Rheinheimer dos Santos ${ }^{4} \quad$ Ademir Calegari $^{5} \quad$ Betania Brum $^{6}$
}

\section{RESUMO}

A flutuação no conteúdo de matéria orgânica do solo é severamente afetada pelo uso e manejo do solo. Em solos física e quimicamente frágeis a destruição da vegetação nativa pode levar a diminuição drástica do estoque de carbono. No entanto, solos jovens que apresentam alta resiliência, quando manejados adequadamente, podem recuperar facilmente os valores originais de carbono. O objetivo deste trabalho foi quantificar os teores de carbono orgânico de um Neossolo e um Chernossolo em decorrência de seu uso, em especial após o desmatamento e revegetação natural. Coletaram-se amostras de duas camadas $(0-5$ e $5-15 \mathrm{~cm})$ em dois solos (Neossolo e Chernossolo) ocorrentes numa pequena bacia hidrográfica com relevo fortemente ondulado, com quatro condições de uso (mata nativa, lavoura nova, lavoura velha e revegetação com capoeira). Avaliaram-se a distribuição granulométrica, a densidade do solo e os teores de carbono orgânico. Os dados foram submetidos à análise estatística considerando um delineamento inteiramente casualizado, num esquema trifatorial (tipos de solos, tipos de usos e camadas amostradas). O estoque de carbono do solo diminuiu após o desmatamento para a inastalação de culturas anuais com baixa adição de resíduos e revolvimento intenso do solo. A revegetação natural das áreas degradadas pelo cultivo convencional recuperou rapidamente o estoque de carbono dos solos, mesmo permanecendo as impressões herdadas da erosão (menor teor de argila) e da aplicação de fertilizantes e corretivos (menor acidez potencial e maior disponibilidade de fósforo e potássio).

Palavras-chave: usos do solo; Neossolos; Chernossolos; fracionamento da matéria orgânica.

\begin{abstract}
The soil organic matter content is severely affected by soil use and management. In physically and chemically fragile soils the destruction of native vegetation can cause a great decrease in the carbon stock. However, soils that present high resilience, when appropriately handled, can easily recover the original values of carbon. The objective of this research was to quantify and analyze organic carbon of young soils in relation to their use, especially those in natural regeneration. Samples of two layers were collected (0-5 and 5-15 $\mathrm{cm}$ ) in two soils (Neossolo and Chernossolo) that occur in a headslope watershed, with four use conditions

1. Engenheiro Agrônomo, Doutorando do Programa de Pós-Graduação em Ciência do Solo, Universidade Federal do Rio Grande do Sul, Av. Bento Gonçalves, 7712, Bairro Agronomia, CEP 91540-000, Porto Alegre (RS). sidineileandro@gmail.com

2. Engenheiro Agrônomo, MSc., Doutorando em Agronomia - Energia na Agricultura, Rua Humberto Milanesi Junior, 1100, CEP 18610-070, Botucatu (SP). bagiottorossato@yahoo.com.br

3. Engenheiro Agrônomo, Doutorando do Programa de Pós-Graduação em Ciência do Solo, Centro de Ciências Rurais, Universidade Federal de Santa Maria, Rua Erly de Almeida Lima, 195, Apto. 401, Bairro Camobi, CEP 95120-105, Santa Maria (RS).copettiufsm@gmail.com

4. Engenheiro Agrônomo, Dr., Professor do Departamento de Solos, Centro de Ciências Rurais, Universidade Federal de Santa Maria, Av. Roraima, 1000, CEP 97105-900, Santa Maria (RS). danilor@smail.ufsm.br

5. Engenheiro Agrônomo, Dr., Rod. Celso Garcia Cid, Km 375, Caixa Postal 481, CEP 86001-970, Londrina (PR). calegari@iapar.br

6. Engenheira Agrônoma, Doutoranda do Programa de Pós-Graduação em Agronomia, Centro de Ciências Rurais, Universidade Federal de Santa Maria, Rua Erly de Almeida Lima, 195, Apto. 401, Bairro Camobi, CEP 95120-105, Santa Maria (RS). agrobetania@yahoo.com.br

Recebido para publicação em 14/07/2009 e aceito em 26/07/2010
\end{abstract}


(forest, new farming, old farming and regeneration). Particle size distribution, soil bulk density and organic carbon were evaluated. The data were submitted to statistical analysis considering a completely randomized design, in tri-factorial outline (soil types, uses and sampled layers). The soil carbon stock decreased with deforestation for annual plantation of crops with little addition of residues and intensive soil turbation. The natural regeneration of degraded soils by conventional tillage recovered the soil carbon stock quickly, even when there remained impressions from erosion (lower clay) and from the application of fertilizers and correctives (lower potential acidity and larger phosphorus and potassium availability).

Keywords: soil uses; Neossolos; Chernossolos; organic matter division.

\section{INTRODUÇ̃̃O}

A qualidade do solo consiste na sua capacidade de funcionar dentro dos limites de um ecossistema natural ou manejado, para sustentar a produtividade de plantas e de animais, manter ou aumentar a qualidade do ar e da água e promover a saúde das plantas, dos animais e dos homens (DORAN, 1997). Um dos principais indicadores da qualidade do solo é o seu conteúdo de carbono orgânico (VEZZANI, 2001; CONCEIÇÃO, 2002), pois promove inúmeras funções químicas, físicas e biológicas que atuam nos sistemas agrícolas e ambientais.

O carbono orgânico do solo pode ser classificado de acordo com diferentes princípios. Sob o ponto de vista das suas transformações quantitativas, Mielniczuck (1999) classificou o estoque de matéria orgânica em compartimentos que expressam diferentes resistências à decomposição e funções que exercem no solo. A matéria orgânica não protegida compreende a biomassa microbiana e fração grosseira, associada às partículas de solo com diâmetro superior a $53 \mu \mathrm{m}(>53 \mu \mathrm{m})$, também denominada fração lábil. A matéria orgânica protegida é aquela associada a minerais com tamanho inferior a $53 \mu \mathrm{m}(>53 \mu \mathrm{m})$ podendo ser subdividida em função do tipo de proteção, estrutural ou coloidal. A matéria orgânica não protegida é responsável pela agregação temporária, é fonte de carbono, elétrons, energia e atua como fonte de nutrientes que compõem a estrutura dos microorganismos. A biomassa microbiana se destaca pela decomposição dos resíduos e pela considerável emissão de $\mathrm{CO}_{2}$ (SCHLESINGER, 1991). Essa fração é facilmente afetada por perturbações do meio e possui um tempo de permanência no solo de 2 a 5 anos. Ela representa aproximadamente um terço do carbono orgânico total do solo.

A matéria orgânica protegida é dependente da magnitude dos compartimentos não protegidos, da intensidade de revolvimento e da textura do solo. A fração estrutural depende ainda do grau de destruição dos agregados e a fração coloidal depende da mineralogia do solo. A matéria orgânica protegida é responsável pela agregação permanente, pela principal fonte de acidez potencial e pela grande capacidade de troca de cátions do solo. Ela pode permanecer no solo por até 100 anos (Mielniczuck, 1999).

As alterações no uso da terra têm, portanto, estreita relação com a dinâmica da matéria orgânica e com o ciclo biogeoquímico dos elementos, modificando a capacidade produtiva desses ambientes (BROWN et al., 1994). Cultivos em áreas desflorestadas, por exemplo, diminuem rapidamente a qualidade do solo, por causa das alterações em componentes sensíveis à desestabilização do sistema provocado por mudanças, especialmente, relacionadas ao revolvimento do solo e redução das taxas de entrada de resíduos pela retirada da mata. O desflorestamento afeta o conteúdo de carbono orgânico pela influência na quantidade e qualidade de biomassa vegetal produzida e incorporada ao solo (LAL, 1996). Logo após a derrubada, o intenso cultivo do solo diminui gradativamente o estoque de carbono, mesmo em solos com altos teores de argila (LAL, 1996; CALEGARI, et al. 2008).

No caso das espécies florestais, observa-se maior capacidade de ciclagem de nutrientes que as plantas de ciclo anual, em virtude do sistema radicular permanente e profundo que absorve elementos de camadas subsuperficiais, retornando-os à superfície pela deposição de serapilheira (HAAG, 1985). Além do aumento da biodiversidade, são notáveis as transformações ambientais no decorrer da sucessão, como a transferência de nutrientes livres do solo para a comunidade biótica ao longo do processo, reduzindo sua perda, a melhoria da estrutura edáfica pela produção de matéria orgânica, além de modificações do microclima (GÓMEZ-POMPA e VAZQUEZ-YANES, 1981).

De acordo com Tresder et al. (2008), o mais

Ci. Fl., v. 21, n. 2, abr.-jun., 2011 
substancial impacto da conversão de sistemas com culturas anuais para áreas reflorestadas é o aumento da biomassa radicular no solo. REEDER et al. (2001) citam que a biomassa radicular pode passar de $0,15 \mathrm{~kg} \mathrm{~m}^{-2}$ em áreas agrícolas para $1,4 \mathrm{~kg} \mathrm{~m}^{-2}$ em áreas com pastagens ou $4,3 \mathrm{~kg} \mathrm{~m}^{-2}$ em áreas de floresta. Geralmente os sistemas perenes possuem um sistema radicular mais denso e fibroso e, desse modo, proporcionam um melhor armazenamento de energia no solo do que as culturas anuais (van VEEN et al., 1991), além de aumentar as espécies com sistema radicular profundo (TRESDER et al., 2008). Moreira e Costa (2004) citam que a revegetação de áreas de clareira aumentam significativamente $o$ teor de matéria orgânica e o conteúdo da biomassa microbiana do solo, a partir do quarto ano de idade, podendo, no entanto, em caso de manejo inadequado da área desmatada, resultar num rápido declínio da capacidade produtiva do solo.

Nesse sentido, o conhecimento da variação dos teores de carbono orgânico no solo em diferentes situações de uso pode auxiliar na escolha de critérios de uso e manejo do solo e preservar sua qualidade. Assim, o presente trabalho teve por objetivo avaliar a variação dos teores de carbono orgânico de solos pela destruição e revegetação natural numa pequena bacia hidrográfica de cabeceira com relevo fortemente ondulado.

\section{MATERIAL E MÉTODOS}

$O$ estudo foi realizado na pequena bacia hidrográfica do Arroio Lino, localizada na encosta basáltica do Rio Grande do Sul, entre a Depressão Central e o Planalto Médio, na latitude $29^{\circ} 28^{\prime} \mathrm{S}$, longitude $53^{\circ} 15^{\prime} \mathrm{W}$, no município de Agudo (Figura 1). O relevo é ondulado a fortemente ondulado com solos predominantemente rasos, classificados em sua grande maioria como Neossolos e Chernossolos (DALMOLIN et al., 2003). O clima da região é do tipo Cfa, segundo a classificação de Köppen, ou seja, clima subtropical úmido sem estiagem. As chuvas são normalmente bem distribuídas variando de 1.300 a $1.800 \mathrm{~mm}^{\mathrm{ano}^{-1}}$ (MALUF, 2000). A vegetação é constituída de mata primária em alguns pontos, além de mata secundária e capoeirões em diversos estágios de sucessão na grande maioria das áreas, visto que grandes extensões de áreas com vegetação permanente foram utilizadas no passado como lavouras. As lavouras de culturas anuais representam $27 \%$ da área da $\mathrm{PBH}$, sendo predominantemente cultivadas com fumo sob preparo convencional do solo, sem nenhuma prática conservacionista e com uso intenso de insumos. A distribuição fundiária da região é baseada na pequena propriedade de produção familiar (PELEGRINI, 2005).

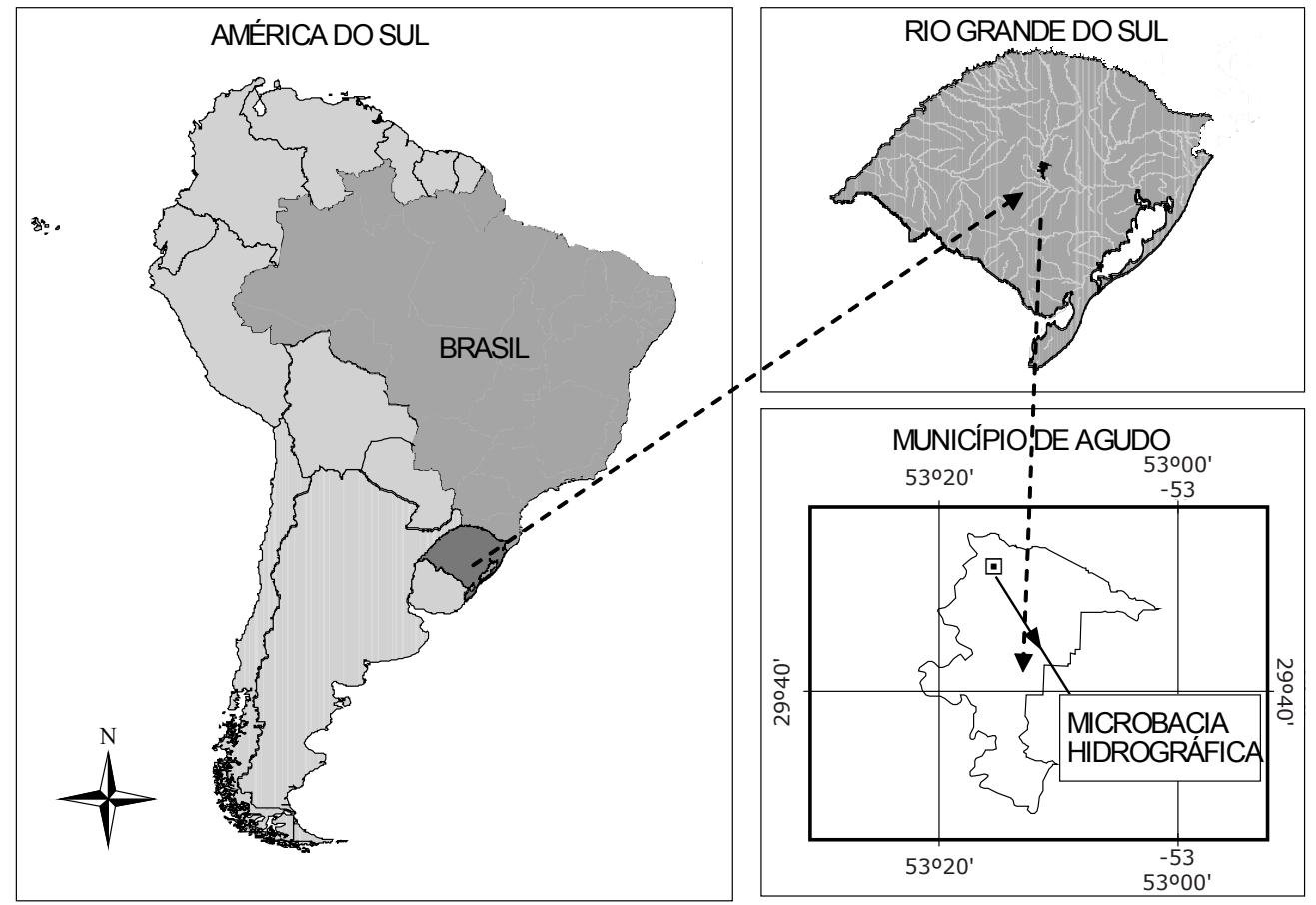

FIGURA 1: Localização da Microbacia Hidrográfica do Arroio Lino, Agudo, RS, Brasil.

FIGURE 1: Arroio Lino's watershed location, Agudo, RS, Brazil. 
A maioria das operações agrícolas é realizada manualmente e/ou com tração animal em razão do relevo fortemente ondulado nas áreas cultivadas. Nessas áreas, não é recomendado o cultivo de culturas anuais, por causa do alto risco de erosão. Porém, como predominam pequenas propriedades, na maioria dos casos, os solos são cultivados intensivamente até atingir níveis de elevada degradação.

A dinâmica de uso das terras da pequena bacia hidrográfica se dá de forma singular, ditada pelas características do solo, relevo, vegetação e, em especial, pelo processo usado pelos produtores de fumo, já que essa cultura ocupa em torno de $70 \%$ da área utilizada com culturas anuais (COPETTI et al., 2005). A pequena bacia hidrográfica estudada abrange uma área de 480 ha, distribuídos em mata nativa (277 ha), lavouras anuais (118 ha) e transição de mata para lavouras ou de lavouras para capoeiras (10 a 15 ha). A singularidade do uso e manejo do solo é a permanência da prática do desmatamentodescapoeiramento, fogo, cultivo intensivo e abandono para revegetação natural. Durante o ciclo de cultivo do fumo, os fumicultores utilizam avançadas tecnologias por um lado (genética das variedades, sistema de cura do fumo extremamente sofisticado, produção de mudas no sistema float, uso intensivo de agrotóxicos e fertilizantes) e por outro lado, descaso absoluto com as questões ambientais, inclusive com a saúde de suas famílias.

Em dezembro de 2006 (período correspondente à maturação do fumo), coletaramse amostras de solo em duas camadas (0-5 e 5-15 $\mathrm{cm}$ ), das duas classes de solos predominantes na pequena bacia hidrográfica - Neossolo Litólico Eutrófico típico e Chernossolo Háplico Órtico típico (DALMOLIN et al., 2003) e em quatro condições de uso dos solos (mata, lavoura nova, lavoura velha e capoeira). O Neossolo amostrado se distribui majoritariamente nas cotas mais elevadas e de maior declividade, enquanto que o Chernossolo predomina nos patamares mais planos e próximos aos cursos de água. Os quatro tipos de uso do solo foram demarcados dentro da mesma encosta e mais próximos possível um do outro. A área de Mata Nativa, 1,9 ha no Neossolo e 0,2 ha no Chernossolo, não foi cultivada há pelo menos 40 anos, era muito densa e apresentava presença de espécies típicas da floresta local como Patagonula americana (guajuvira), Parapiptadenia rigida (angico), Myrocarpus frondosus (cabreúva), Cordia trichotoma (louro), Cedrela fissilis (cedro), Apuleia leiocarpa (grápia) e Luehea divaricata (açoitacavalo) e, próximo aos leitos de drenagem, touceiras de Bambusa trinii (taquaraçu). A área de Lavoura Nova, sobre 0,05 ha no Neossolo e 0,3 ha no Chernossolo, refere-se a uma área recém-desmatada e queimada, onde havia sido realizado apenas dois anos de cultivo (feijão, milho ou fumo). A área de Lavoura Velha, sobre 0,8 ha no Neossolo e 1,7 ha no Chernossolo, havia sido cultivada intensamente e com revolvimento constante do solo, uso de altas doses de fertilizantes e agrotóxicos nos últimos 15 anos, especialmente com a cultura do fumo. A área de Capoeira, compreendendo 0,06 ha no Neossolo e 0,3 ha no Chernossolo, foi intensamente cultivada e abandonada há seis anos. Ela se encontrava num estágio inicial de recuperação e o solo estava totalmente coberto e com o estabelecimento de espécies pioneiras como Dalbergia frutencens (Rabo-de-bugio), Casearia sylvestris (Guaçatonga), Jacaranda micrantha (Caroba-do-mato), Banara tomentosa (Banara), Sapium glandulatum (Pauleiteiro), Trema micrantha (Grandiúva), Hovenia dulcis (Uva-do-japão), Cupania vernalis (Camboatávermelho), Allophylus edulis (Chal-chal), Bauhinia forficata (Pata-de-vaca), entre outras.

Em cada uso do solo, nos dois tipos de solos, coletaram-se três subamostras para compor uma amostra. O solo foi seco ao ar, passado em peneira de $2 \mathrm{~mm}$ para separar a fração grosseira da fina, na qual foi determinada a composição granulométrica pelo método da pipeta (EMBRAPA, 1997). A dispersão foi baseada no uso de hidróxido de sódio 1 mol L$^{-1}$ e agitação mecânica horizontal durante 4 horas. Após a agitação, o conteúdo foi passado em peneira de $53 \mu \mathrm{m}$ e a fração que permaneceu na peneira correspondeu à fração maior que $53 \mu \mathrm{m}$, e a que passou foi transferida para proveta de $1000 \mathrm{ml}$, e a fração argila (menor que $2 \mu \mathrm{m}$ ) foi determinada pela sedimentação (lei de Stokes) e a fração silte pela diferença entre a fração maior que $53 \mu \mathrm{m}$ e menor $2 \mu \mathrm{m}$. Também foi determinada a densidade do solo nas amostras coletadas em cilindros (3,0 $\mathrm{cm}$ de altura e 4,88 $\mathrm{cm}$ de diâmetro). Os teores de carbono total do solo e das frações granulométricas ( $>53 \mu \mathrm{m}$ e $<53 \mu \mathrm{m}$ ) foram determinados por oxidação úmida em tubos de digestão em bloco pré-aquecido, conforme Rheinheimer et al. (2008).

Para análise estatística, considerou-se o delineamento inteiramente casualizado em esquema bifatorial e com três repetições. O fator A foi

Ci. Fl., v. 21, n. 2, abr.-jun., 2011 
constituído pelos dois tipos de solos, o fator D pelos quatro usos dos solos. A análise se procedeu nas duas camadas de solo amostrado. A comparação de médias foi realizada pelo teste de Tukey, a 5\% de probabilidade de erro.

\section{RESULTADOS E DISCUSSÃO}

\section{Alteração na granulometria: erosão seletiva}

A proporção granulométrica dos dois solos estudados foi alterada com o tipo de uso. A quantidade de areia na condição de Lavoura Velha foi maior e diferiu estatisticamente dos demais usos, para os dois solos. A fração argila apresentou maior conteúdo nas áreas de mata, diminuindo seus valores com a intensidade de uso dada ao solo, variando de $225,4 \mathrm{~g} \mathrm{~kg}^{-1}$ na mata para 109,7 $\mathrm{g} \mathrm{kg}^{-1}$ na área de lavoura velha no Neossolo e de 199,5 $\mathrm{g} \mathrm{kg}^{-1}$ para $153,9 \mathrm{~g} \mathrm{~kg}^{-1}$ no Chernossolo considerando a média das duas camadas de solo (Tabela 1). A variação nos teores de argila para o Chernossolo não foi tão intensa em virtude desse solo ser mais intemperizado, e geralmente estar alocado em posições na paisagem com relevo menos ondulado.
A cultura do fumo exige aplicação de altas doses de fertilizantes nitrogenados na forma nítrica. Para tal, usa-se o Salitre do Chile que contém, além do potássio, grandes quantidades de sódio. Esse elemento é um forte dispersante por aumentar a espessura da dupla camada difusa das partículas de tamanho coloidal e, com isso, diminui a estabilidade dos agregados (BAGARELLO et al., 2006). A combinação de revolvimento intensivo do solo com uso desse tipo de fertilizante tem sido responsável pelo rompimento dos agregados, favorecendo tanto a erosão seletiva dos constituintes mais finos quanto à liberação do carbono orgânico protegido acelerando a mineralização (MELLO, 2006). As perdas de solo e água por erosão hídrica manifestamse de forma variável dependentes da interação do clima, solo, topografia, cobertura e manejo do solo e práticas conservacionistas (WISCHMEIER \& SMITH, 1978). Em um trabalho realizado na mesma microbacia deste estudo, mensurando a quantidade de material erodido em uma área sob plantio convencional de fumo, Pellegrini (2006) encontrou perdas de solo de até $500 \mathrm{~g} \mathrm{~m}^{-2} \mathrm{em}$ períodos de elevada precipitação. Adicionalmente, a presença de grandes quantidades de argilominerais

TABELA 1: Composição granulométrica dos dois solos (Neossolo e Chernossolo) em quatro usos (Mata Nativa, Capoeira, Lavoura Velha e Lavoura Nova) e em duas camadas $(0-5$ e 5-15 cm).

TABLE 1: Granulometric composition of soils (Neossolo e Chernossolo) in four uses (Natural Forest, Revegetation, Intensive Soil Use with Crop and Recent Use with Crop) and in two layers (0-5 and $5-15 \mathrm{~cm})$

\begin{tabular}{|c|c|c|c|c|c|c|c|c|c|c|c|c|}
\hline \multirow[t]{2}{*}{ Usos } & \multicolumn{2}{|c|}{ Areia } & \multicolumn{2}{|c|}{ Silte } & \multicolumn{2}{|c|}{ Argila } & \multicolumn{2}{|c|}{ Areia } & \multicolumn{2}{|c|}{ Silte } & \multicolumn{2}{|c|}{ Argila } \\
\hline & \multicolumn{6}{|c|}{------- 0 - 5 cm --------- } & \multicolumn{6}{|c|}{---------- 5 - 15 cm --------- } \\
\hline & \multicolumn{12}{|c|}{ Neossolo } \\
\hline Mata & 324,9 & $\mathrm{~b}$ & 437,6 & $\mathrm{a}$ & 237,5 & $\mathrm{a}$ & 273,5 & $\mathrm{c}$ & 513,1 & a & 213,4 & $\mathrm{a}$ \\
\hline Capoeira & 341,2 & $\mathrm{~b}$ & 486,0 & $\mathrm{a}$ & 172,8 & $\mathrm{~b}$ & 337,1 & $\mathrm{~b}$ & 507,2 & a & 155,8 & $\mathrm{~b}$ \\
\hline Lav. Nova & 336,4 & $\mathrm{~b}$ & 504,9 & $\mathrm{a}$ & 158,7 & $\mathrm{~b}$ & 321,9 & bc & 515,8 & a & 162,3 & $\mathrm{~b}$ \\
\hline \multirow[t]{2}{*}{ Lav. Velha } & 547,5 & a & 348,2 & $\mathrm{~b}$ & 104,2 & $\mathrm{c}$ & 506,9 & $\mathrm{a}$ & 378,0 & $\mathrm{~b}$ & 115,1 & $\mathrm{c}$ \\
\hline & \multicolumn{12}{|c|}{ Chernossolo } \\
\hline Mata & 282,1 & $\mathrm{~b}$ & 514,4 & $\mathrm{a}$ & 203,5 & a & 287,5 & $\mathrm{~b}$ & 516,9 & $\mathrm{a}$ & 195,6 & $\mathrm{a}$ \\
\hline Capoeira & 334,5 & $a b$ & 504,5 & $\mathrm{a}$ & 161,0 & $\mathrm{~b}$ & 302,3 & $\mathrm{~b}$ & 540,4 & $\mathrm{a}$ & 157,2 & b \\
\hline Lav. Nova & 341,2 & $a b$ & 507,1 & $\mathrm{a}$ & 151,7 & $\mathrm{~b}$ & 341,1 & $a b$ & 501,2 & $\mathrm{a}$ & 157,7 & $\mathrm{~b}$ \\
\hline Lav. Velha & 417,2 & $\mathrm{a}$ & 428,0 & $\mathrm{~b}$ & 154,8 & $\mathrm{~b}$ & 414,6 & $\mathrm{a}$ & 432,4 & $\mathrm{~b}$ & 153,0 & $\mathrm{~b}$ \\
\hline CV \% & 7,8 & & 7,2 & & 7,9 & & 7 & & 5 , & & 7,9 & \\
\hline
\end{tabular}

Em que: Médias seguidas pela mesma letra, na coluna, para cada solo, não diferem significativamente pelo teste de Tukey, ao nível de $5 \%$ de probabilidade de erro. 
2:1 expansivos em ambos os solos (GONÇALVES, 2007), oferece pouca proteção química ao carbono orgânico do solo, em razão do fato de que ambas as partículas, embora de tamanho coloidal, têm potencial elétrico negativo. Isso favorece a destruição dos agregados e, por consequência, o transporte seletivo, tanto de argila quanto do carbono orgânico (NEARING, 1997).

\section{Alteração no teor de carbono orgânico nas diferentes frações granulométricas}

O impacto das mudanças no uso dos solos é mais evidente nos teores de carbono orgânico associado às partículas com tamanho maior que $53 \mu \mathrm{m}$, em ambas as camadas de solo amostradas. A diminuição nos teores de carbono orgânico no Neossolo foi significativa entre a área de Mata Nativa e a área com apenas dois anos de cultivo (Lavoura Nova), reduzindo de 20,71 para 9,95 g $\mathrm{kg}^{-1}$ de solo (52\%) na camada de $0-5 \mathrm{~cm}$ da fração maior que $53 \mu \mathrm{m}$. Na Lavoura Velha a diminuição no teor de carbono orgânico foi de $75 \%$ em relação ao teor na Lavoura Nova, o qual apresentou apenas $2,52 \mathrm{~g} \mathrm{~kg}^{-1}$ de solo (equivalente a $12 \%$ do teor encontrado na área de Mata Nativa e $25 \%$ na área de Lavoura Nova). No Chernossolo, a diminuição do teor de carbono orgânico da fração maior 53 $\mu \mathrm{m}$ do solo da camada $0-5 \mathrm{~cm}$, foi de $46 \%(12,44$ para $6,71 \mathrm{~g} \mathrm{~kg}^{-1}$ de solo) com apenas dois anos de cultivo (Lavoura Nova) em relação à Mata Nativa. Comparando a Lavoura Nova com a Lavoura Velha o decréscimo foi de $50 \%\left(6,71\right.$ para $3,36 \mathrm{~g} \mathrm{~kg}^{-1}$ de solo) (Tabela 2).

$\mathrm{Na}$ área de Lavoura Velha, a perda de carbono orgânico para ambas as frações foi mais intensa que na área de Lavoura Nova. A maior variação do carbono orgânico na fração areia em relação à fração associada ao silte e argila, está relacionada ao grau de proteção do carbono orgânico, que associado à fração argila é menos afetado pelas práticas de manejo dadas a esse solo.

Segundo Lal (1996), logo após a derrubada da vegetação, o efeito no conteúdo de carbono orgânico pode ser pequeno ou ainda nulo, contudo, na área de Lavoura Nova, verificou-se que além da decomposição do carbono orgânico lábil (maior que $53 \mu \mathrm{m}$ ), houve também a decomposição do carbono orgânico protegido (menor que $53 \mu \mathrm{m}$ ), mostrando que nesses solos (solos jovens) o efeito no decréscimo do conteúdo de carbono ocorre de forma rápida, em ambas as frações.
Pelo fato desses solos serem pedogeneticamente jovens, sua constituição mineralógica é predominantemente de minerais 2:1 (GONÇALVES, 2007) apresentando baixa interação com a matéria orgânica. Com isso, somente uma pequena parte dos minerais presentes, sobretudo na fração argila, são capazes de formar complexos com a matéria orgânica, conferindo-lhe maior proteção. Além disso, por ser um solo raso e com elevada declividade, pelos intensos efeitos da erosão, a perda de carbono orgânico é muito rápida e a capacidade de retenção de carbono orgânico na fração argila é pequena, conferindo a esse solo, quando malmanejado, elevado potencial de degradação de carbono orgânico e da qualidade do solo.

Embora o carbono orgânico associado à fração mais fina de solo possua maior capacidade de formar complexos organominerais, observou-se que,nas áreas com vários anos de cultivo, houve alta decomposição do carbono dessa fração. Isso pode estar associado à desagregação provocada pelo revolvimento do solo e pela baixa interação entre a fração argila desse solo e o carbono orgânico. Já para o Chernossolo, por ser um solo mais intemperizado e apresentar menos variação nos teores de argila com as mudanças de uso do solo, observou-se menor flutuação nos teores de carbono orgânico associados à fração mais fina de solo, evidenciando maior energia de ligação da fração argila com a fração orgânica, e propiciando maior proteção à matéria orgânica nesse solo.

Após um período de revegetação (Capoeira), os teores de carbono orgânico na fração maior que $53 \mu \mathrm{m}$ elevaram-se significativamente comparativamente à Lavoura Velha. No Neossolo, os teores passaram de 2,52 para $15,46 \mathrm{~g} \mathrm{~kg}^{-1}$ de solo, representando aumento de $513 \%$ e no Chernossolo, de 3,36 para $7,37 \mathrm{~g} \mathrm{~kg}^{-1}$ de solo (119\%) (Tabela 2). Quando comparados a Lavoura Velha com Capoeira, a recuperação de carbono foi significativa para todas as frações no Neossolo. Já para o Chernossolo, a recuperação só não foi significativa para o carbono orgânico associado à menor fração do solo $(<2 \mu \mathrm{m})$. A intensidade da recuperação, por sua vez, quando comparamos a Capoeira com a Mata Nativa foi, de modo geral, menor no Chernossolo que no Neossolo. Neste, para ambas as fraçõe, o teor de carbono orgânico na Capoeira não diferiu significativamente dos teores da Mata Nativa, enquanto que, para o Chernossolo, os valores de carbono orgânico não diferiram 
TABELA 2: Conteúdo de carbono orgânico em diferentes tamanhos de partículas ( $>53 \mu \mathrm{m},<53 \mu \mathrm{m}$ e $<2 \mu \mathrm{m}$ ) dos dois solos (Neossolo e Chernossolo) em quatro usos (Mata Nativa, Capoeira, Lavoura Velha e Lavoura Nova) e em duas camadas (0-5 e 5-15 cm).

TABLE 2: Organic carbon content in different particle sizes $(>53 \mu \mathrm{m}<53 \mu \mathrm{m}$ and $<2 \mu \mathrm{m})$ of two soils (Neossolo e Chernossolo) in four uses (Natural Forest, Revegetation, Intensive Soil Use with Crop and Recent Use with Crop) and in two layers (0-5 and 5-15 cm).

\begin{tabular}{|c|c|c|c|c|c|c|}
\hline \multirow[t]{3}{*}{ Usos } & $>53 \mu \mathrm{m}$ & $<53 \mu \mathrm{m}$ & $<2 \mu \mathrm{m}$ & $>53 \mu \mathrm{m}$ & $<53 \mu \mathrm{m}$ & $<2 \mu \mathrm{m}$ \\
\hline & \multicolumn{6}{|c|}{ gramas de carbono orgânico por kilograma de solo } \\
\hline & \multicolumn{3}{|c|}{------------------- 0-5 cm --------------- } & \multicolumn{3}{|c|}{------------------ 5-15 cm -------------- } \\
\hline & \multicolumn{6}{|c|}{ Neossolo } \\
\hline Mata & $20,71 \mathrm{a}$ & 27,09 a & 4,33 a & $13,59 \mathrm{a}$ & $26,51 \mathrm{a}$ & 4,12 a \\
\hline Capoeira & $15,46 \mathrm{ab}$ & 27,40 a & $4,17 \mathrm{ab}$ & $9,12 \mathrm{~b}$ & $23,93 \mathrm{ab}$ & $4,24 \mathrm{a}$ \\
\hline Lav. Nova & $9,95 \quad b$ & $22,30 \mathrm{a}$ & $3,03 \mathrm{ab}$ & $8,64 \mathrm{~b}$ & $19,76 \quad b$ & 4,38 a \\
\hline \multirow[t]{2}{*}{ Lav. Velha } & $2,52 \quad \mathrm{c}$ & $7,89 \quad b$ & $2,03 \quad b$ & 2,68 & 8,40 & $2,31 \quad b$ \\
\hline & \multicolumn{6}{|c|}{ Chernossolo } \\
\hline Mata & 12,44 a & 27,38 a & $10,19 \mathrm{a}$ & $2,92 \mathrm{a}$ & $18,06 \mathrm{a}$ & $9,47 \mathrm{a}$ \\
\hline Capoeira & $7,37 \mathrm{ab}$ & $16,80 \quad b c$ & $6,54 \mathrm{~b}$ & $4,29 \mathrm{a}$ & $14,70 \mathrm{a}$ & $6,74 \quad b$ \\
\hline Lav. Nova & $6,71 \mathrm{ab}$ & $21,02 \mathrm{ab}$ & $6,88 \quad b$ & 3,37 a & 18,35 a & $6,84 \quad b$ \\
\hline Lav. Velha & $3,36 \quad b$ & 10,31 & $6,25 \quad b$ & $2,68 \mathrm{a}$ & $9,62 \quad b$ & $6,10 \quad b$ \\
\hline CV \% & 23,8 & 14,6 & 14,5 & 34,8 & 13,4 & 14,4 \\
\hline
\end{tabular}

Em que: Médias seguidas pela mesma letra, na coluna, para cada solo, não diferem significativamente pelo teste de Tukey, em nível de 5\% de probabilidade de erro.

apenas na fração maior que $53 \mu \mathrm{m}$, na camada de 0-5 cm. Embora o Neossolo tenha mostrado maior variação no teor de carbono orgânico, na fração menor que $53 \mu \mathrm{m}$, a recuperação chegou próxima a $100 \%$, quando se compararam a Capoeira com a Mata Nativa para ambas as camadas. Isso mostra que, apesar de haver maior degradação no Neossolo quando usados de forma mais intensiva, há maior velocidade de recuperação dos teores de carbono orgânico associado à fração menor que $53 \mu \mathrm{m}$ após o abandono das áreas cultivadas.

\section{Alteração no estoque de carbono orgânico}

$\mathrm{O}$ uso inadequado do solo com culturas anuais, com predomínio do tabaco, aliado ao intenso revolvimento do solo da camada 0-15 cm (arações, gradagens e capinas) acarretou drástica diminuição do estoque de carbono orgânico do solo. A derrubada da Mata Nativa, seguida da queima e revolvimento para a instalação de culturas anuais (Lavoura Nova), diminuiu o estoque de carbono em 46 e $33 \%$ respectivamente no Neossolo e Chernossolo (Tabela 3). A sequência de cultivos com o tabaco por aproximadamente 15 anos (Lavoura Velha), partindo de Lavoura Nova, acelerou o esgotamento dos estoques de carbono orgânico (decréscimo de $72 \%$ no Neossolo - 59,55 para $16,49 \mathrm{Mg} \mathrm{ha}^{-1} \mathrm{e}$ de $74 \%$ - 45,77 para $11,80 \mathrm{Mg} \mathrm{ha}^{-1}$ no Chernossolo). O uso do solo por dois anos (Lavoura Nova) depois da derrubada da Mata Nativa diminuiu em 59 e 32\% o estoque de carbono orgânico, respectivamente, para o Neossolo e o Chernossolo na camada de 0-5 cm. Na camada de $5-15 \mathrm{~cm}$, o decréscimo no estoque foi similar para os dois solos (36 e 34\%, respectivamente, para o Neossolo e Chernossolo). A continuação de uso com culturas anuais e sem adoção de práticas mínimas de conservação do solo (Lavoura Velha) acelerou a decomposição da matéria orgânica de ambos os solos, inclusive daquele sequestrado no solo das camadas mais profundas (Tabela 3). Lal (1996), estudando solos frágeis na Nigéria (Alfisol $=$ Argissolo), da mesma forma, afirmou que o intenso cultivo do solo logo após o desflorestamento em solos arenosos diminui gradativamente o carbono orgânico, podendo atingir perdas de 25 a $60 \%$ nos primeiros $5 \mathrm{~cm}$ superficiais do solo e 15 a $30 \%$ na camada de $5-15 \mathrm{~cm}$. 
TABELA 3: Estoque de carbono orgânico dos dois solos (Neossolo e Chernossolo) em seus quatro usos (Mata Nativa, Capoeira, Lavoura Velha e Lavoura Nova) e em duas camadas $(0-5$ e 5-15 cm).

TABLE 3: Organic carbon storage in the soils (Neossolo e Chernossolo) in its four uses (Natural Forest, Revegetation, Intensive Soil Use with Crop and Recent Use with Crop) and in two layers (0-5 and $5-15 \mathrm{~cm}$ ).

\begin{tabular}{|c|c|c|c|c|c|c|c|c|c|}
\hline \multirow{3}{*}{ Usos } & \multicolumn{6}{|c|}{ Neossolo } & \multicolumn{3}{|c|}{ Chernossolo } \\
\hline & $0-5 \mathrm{~cm}$ & & $5-15 \mathrm{cn}$ & & $0-15 \mathrm{cr}$ & & $0-5 \mathrm{~cm}$ & $5-15 \mathrm{~cm}$ & $0-15 \mathrm{~cm}$ \\
\hline & \multicolumn{9}{|c|}{ Mg de carbono orgânico ha-1 } \\
\hline Mata & 48,30 & & 62,63 & & 110,93 & $\mathrm{a}$ & 25,39 a & $42,73 \mathrm{a}$ & $68,12 \mathrm{a}$ \\
\hline Capoeira & 30,26 & $\mathrm{~b}$ & 50,69 & $\mathrm{ab}$ & 80,95 & $\mathrm{~b}$ & $14,37 \mathrm{ab}$ & $13,96 \quad b c$ & $28,33 \quad b c$ \\
\hline Lavoura nova & 19,75 & $\mathrm{bc}$ & 39,80 & $\mathrm{~b}$ & 59,55 & $\mathrm{~b}$ & $17,39 \mathrm{ab}$ & $28,38 \mathrm{ab}$ & $45,77 \mathrm{ab}$ \\
\hline Lavoura velha & 5,40 & $\mathrm{c}$ & 11,09 & $\mathrm{c}$ & 16,49 & $\mathrm{c}$ & $3,51 \quad b$ & 8,29 & 11,80 \\
\hline CV (\%) & 26 & & 22 & & 27 & & 26 & 22 & 24 \\
\hline
\end{tabular}

Em que: Médias seguidas pela mesma letra, na coluna, não diferem significativamente pelo teste de Tukey, ao nível de $5 \%$ de probabilidade de erro.

Quando abandonadas, a revegetação natural do solo (Capoeira) recuperou rapidamente o estoque de carbono orgânico das áreas intensamente cultivadas (Lavoura Velhas), especialmente no Neossolo (Tabela 3). Em apenas seis anos de revegetação os estoques de carbono orgânico do solo da camada de $0-15 \mathrm{~cm}$ das Lavouras Velhas aumentaram em 390\% (16,49 para 80,95 Mg $\mathrm{ha}^{-1}$ no Neossolo) em $140 \%$ (11,80 para 28,33 Mg ha ${ }^{-1}$ no Chernossolo). Johnson et al. (2001) ao estudar o estoque de carbono de florestas secundárias, observaram que clareiras com 10 anos de idade apresentaram conteúdo de carbono orgânico, na camada de $0-10 \mathrm{~cm}$, semelhante ao da floresta primária. Entretanto, essa recuperação é dependente das entradas e saídas de carbono orgânico do sistema, e da condição inicial da área. Como a velocidade de recuperação de carbono orgânico, depende do ecossistema em que tal área está inserida, há uma dificuldade na comparação de estudos realizados em diferentes ecossistemas.

A decomposição da serrapilheira acumulada na superfície proporciona maior entrada de carbono orgânico no solo da camada de $0-5 \mathrm{~cm}$. O abandono de áreas de cultivos antigas (Lavoura Velha) por apenas seis anos (Capoeira) proporcionou recuperação do estoque de carbono orgânico de 5,40 para 30,26 $\mathrm{Mg} \mathrm{ha}^{-1}$ e de 3,51 para 14,37 $\mathrm{Mg}^{-}$ ${ }^{1}$, representando 460 e $309 \%$, respectivamente, no Neossolo e Chernossolo (Tabela 3). Já na camada de 5-15 cm, o aumento no estoque de carbono orgânico foi de $357 \%$ no Neossolo e de apenas
$68 \%$ no Chernossolo. Se por um lado, o aumento do carbono orgânico é maior na camada superficial do solo, também a mineralização desse carbono é facilitada pelo uso inadequado comparativamente aquele armazenado nas camadas mais profundas do solo.

\section{CONCLUSÕES}

A derrubada da mata nativa, seguida de queima e cultivo por apenas dois anos diminui drasticamente o estoque de carbono do solo.

$\mathrm{O}$ carbono orgânico associado à fração de solo maior que $53 \mu \mathrm{m}$ é mais afetado pelas mudanças de uso do solo do que aquele associado a frações mais finas;

$\mathrm{O}$ carbono orgânico associado às frações finas do solo $(<53 \mu \mathrm{m} \mathrm{e}<2 \mu \mathrm{m})$ está sujeito às perdas por causa da intensa mobilização do solo e da baixa capacidade de proteção dos argilominerais presentes nos Neossolos e Chernossolos da encosta basáltica do Rio Grande do Sul, entre a Depressão Central e o Planalto Médio.

A revegetação natural, em um período de tempo de apenas seis anos, é suficiente para elevar os teores de carbono orgânico total a níveis próximos ao da mata nativa.

\section{REFERÊNCIAS BIBLIOGRÁFICAS}

BAGARELLO, V. et al. Filed and laboratory approaches for determining sodicity effects on saturated soil hydraulic conductivity. Geoderma, 
Amsterdam, v. 130, p. 1-13. 2006.

BROWN, S. et al. Soil biological processes in tropical ecossystems. In: WOOMER, P. L.; SWIFT, M. J. (Eds.) The biological management of tropical soil fertility. Chichester: John Wiley \& Sons, 1994. p. 15-46.

CALEGARI, A. et al. Impact of Long-Term NoTillage and Cropping System Management on Soil Organic Carbon in an Oxisol: A Model for Sustainability. Agronomy Journal, v. 100, p. 10131019, 2008.

CAMBARDELlA, C. C.; ElliotT, E. T. Particulate soil organic-matter changes across a grassland cultivation sequence. Soil Science Society of America Journal, v. 56, p. 777-783, 1992.

CONCEIÇÃO, P. C. Indicadores de qualidade do solo visando a avaliação de sistemas de manejo do solo. Santa Maria: UFSM, 2002. 125 p.

COPETTI, A. C. C. et al. Uso e ocupação de terras em pequenas unidades de produção familiar com fortes restrições ambientais. In: I CONGRESSO INTERNACIONAL DE DESENVOLVIMENTO RURAL E AGROINDÚSTRIA FAMILIAR, 2005, São Luiz Gonzaga. Anais..., 2005. v. 1.

DALMOLIN, R. S. D. et al. Levantamento semidetalhado de solos da microbacia do arroio Lino - município de Agudo (RS). Santa Maria: UFSM, 2003. 84 p.

DORAN, J. W. Soil quality and sustainability. In: CONGRESSO BRASILEIRO DE CIÊNCIA DO SOLO, 26, 1997, Rio de Janeiro. Palestras... Rio de Janeiro: Sociedade Brasileira de Ciência do Solo, 1997. 1 CD-ROM.

EMBRAPA. Manual de métodos de análises de solo. 2. ed. Rio de Janeiro: Ministério da Agricultura e do Abastecimento, 1997. 212 p.

GÓMEZ-POMPA, A. G.; VÁZQUEZ-YANES, C. N. Successional studies of a rain forest in México. In: WEST, D. C.; SCHUGART, H. H.; BOTKIN, D. B. (eds.). Forest concepts and application. New York: Springer-Verlag, 1981. p. 247-266.

GONÇALVES, C. S. Caracterização de sedimentos e de contaminantes numa microbacia hidrográfica antropizada. 2007. 94 f. Tese (Doutorado em Ciência do Solo)-Universidade Federal de Santa Maria, Santa Maria, 2007.

HAAG, H. P. Ciclagem de nutrientes em florestas tropicais. Campinas: Fundação Cargill, 1985. 144p. JOHNSON C. M.; et al. Carbon and nutrient storage in primary and secondary forests in eastern Amazônia. Forest Ecology and Management, v. 5225, p. 1-8. 2001.
LAL, R. Land use and soil management effects on soil organic matter dynamics on Alfisols in Western Nigéria. In: LAL, R. et al. Soil processes and the carbon cicle. Advances in soil science, 1996. p. 109-126.

MALUF, J. R. T. Nova classificação climática do Estado do Rio Grande do Sul. Revista Brasileira de Agrometeorologia, v. 8, p. 141-150, 2000.

MELLO, R. F. L. Complexidade e sustentabilidade: subsídio para a discussão. In: CONGRÉS INTERLATIN POUR LA PENSÉE COMPLEXE, 1998, Rio de Janeiro. Disponível em: www.complexus. org/rio. Acesso em julho de 2010.

MIELNICZUK, J. Matéria orgânica e a sustentabilidade de sistemas agrícolas. In: SANTOS, G. A.; CAMARGO, F. A. O., eds. Fundamentos da matéria orgânica do solo. Ecossistemas tropicais e subtropicais. Porto Alegre: Genesis, 1999. p. 1-8. MOREIRA, A.; COSTA D. G. Dinâmica da matéria orgânica na recuperação de clareiras da floresta amazônica. Pesquisa Agropecuária Brasileira, Brasília, v. 39, n. 10, p. 1013-1019, 2004.

NEARING, M. A. A single, continuous function for slope steepness influence on soil loss. Soil Science Society of America Journal, v. 61, n. 3, p. 917919, 1997.

PELLEGRINI, A. Sistemas de cultivo da cultura do fumo com ênfase às práticas de manejo e conservação do solo. 2006. 90 f. Dissertação (Mestrado em Ciência do Solo)-Universidade Federal de Santa Maria, Santa Maria, 2006.

PELLEGRINI, J. B. R. Fósforo na água e no sedimento na microbacia hidrográfica do Arroio Lino - Agudo - RS. 2005. 85 f. Dissertação (Mestrado em Ciência do Solo)-Universidade Federal de Santa Maria, Santa Maria, 2005.

REEDER, J. D. et al. Root biomass and microbial processes, p. 139-166. In: FOLLETT, R.F. et al. (Ed). The potential of U.S grazing lands to sequester carbon and mitigate the greenhouse effect. Boca Raton: CRC Press, 2001.

RHEINHEIMER, D. S.; et al. Comparação de métodos de determinação de carbono orgânico total no solo. Revista Brasileira de Ciência do Solo, Viçosa, v. 32, p. 435-440, 2008.

SCHLESINGER, W. H. Biogeochemistry and analysis of global change. San Diego: Academic Press, 1991.

TRESDER, K. K. et al. The contribuition of root exudates, symbionts, and detritus to carbon sequestration, p. 145-162. In: ZOBEL, R. W; WRIGHT, S. F (Ed). Roots and soil management: 
Interactions betwen roots and the soil. Agronomy monograph, n. 48, 2008.

Van VEEN, J. A. et al. Carbon fluxes in plant-soil systems at elevated atmospheric $\mathrm{CO}_{2}$ levels. Ecology Applications, v. 2, p. 175-181, 1991.

VEZZANI, F. Qualidade do sistema solo na produção agrícola. 2001. 184 f. Tese (Doutorado em Ciência do Solo)-Universidade Federal do Rio Grande do Sul, Porto Alegre, 2001.

WISCHMEIER, W. H.; SMITH, D. D. Predicting rainfall erosion losses: a guide to conservation planning. Washington: United States Department of Agriculture, 1978. 58 p. .

Ci. Fl., v. 21, n. 2, abr.-jun., 2011 